\title{
High Satisfaction with Family Planning Health Education Among Women of Reproductive Age in Tanzania: An Exit Survey
}

\author{
Evelyne W. Lutainulwa, Larry O. Akoko, Amani Anaeli
}

\section{ABSTRACT}

\begin{abstract}
Background: Reproductive and child health clinic attendance is vital in offering family planning health education among women of reproductive age in Tanzania. During these visits, group education sessions on modern contraception is offered to women before receiving the specific services they went for. Those who show interest with modern contraception proceed to individualized sessions on adopting one of the methods. Therefore, being satisfied during the group session is paramount to adopting modern contraception. This study therefore sought to assess the level of client satisfaction with the family planning health education among women of reproductive age from selected clinics in Dar es Salaam.
\end{abstract}

Methodology: This was an observational study conducted in selected Reproductive Health clinics in three municipalities within Dar es Salaam region. Facilities were grouped by districts and ownership from which one third were systematically picked to provide 8 participants each. Interviewer led completion of the study tool was employed to assess satisfaction parameters. Analysis on satisfaction was all or none from a 5-point rating scale and association calculated with significance set at a p-value of less than $5 \%$ and $95 \%$ confidence interval.

Results: There was a general higher satisfaction with the family health education offered during the visit period. Satisfaction with family planning health education was significantly higher among women with higher parity ( $p=0.009)$, employed ( $p=0.00001$ ), and were attended to by a clinician $(p=0.0006)$. A significant disparity within municipalities was also noted $(p=0.005)$. Private facilities, shorter time in facilities, and non-cash payments did not significantly influence satisfaction.

Conclusion: Family planning health education satisfaction is high among women of the reproductive age group in Dar es Salaam clinics. We need to explore how this satisfaction is translated to reduce the unmet needs for modern contraception in Tanzania. Furthermore, whether this high satisfaction translates into good knowledge remains unexplored.

Keywords: Family Planning, Health education, modern contraception, satisfaction.

\section{INTRODUCTION}

An unmet need for contraception points to the gap between women's reproductive wish to avoid pregnancy and their contraceptive behavior. Unmet needs for modern contraception is high especially in Low and Middle-income countries (LMICs) [1]. However, recent trends have suggested an increase in women who choose to use modern contraception [2]. By 2010, about $12.3 \%$ of women were experiencing an unmet need for contraception [2]. Accordingly, 210 million women of reproductive in LMICs who would want to avoid, or delay childbirth are not using any contraception [3], [4]. The unmet needs for contraception are partly shown by the 47,000 deaths due to unsafe abortion witnessed globally in 2008, with LMICs having the biggest share [5].
Submitted : February 9, 2021

Published : February 19, 2021

ISSN: $2593-8339$

DOI: $10.24018 /$ ejmed.2021.3.1.712

Dr. Evelyne W Lutainulwa

Muhimbili University of Health and Allied Sciences, Tanzania.

Former Public health student and graduate (e-mail: evewilly200@yahoo.com) Dr. Larry O. Akoko*

Senior Lecturer in Surgery, Muhimbili University of Health and Allied Sciences, Tanzania.

e-mail: akokole12@gmail.com)

Dr. Amani Anaeli

School of Public Health, Muhimbili University of Health and Allied Sciences, Tanzania.

(e-mail: amaniananeli@yahoo.co.uk)

*Corresponding Author
Local governments and development partners across the globe have invested much in resources and policy level to make sure there is unhindered availability of modern contraception [6]. One third of maternal deaths are preventable by modern contraception [7] and 1.6 million lives of children under the age of five years are saved if spaced at least three years apart [8]. But clients have to show readiness to take up modern contraception for the intended advantages to be realized. Why clients are not taking up modern contraception becomes an important issue amongst practitioners and the wider stakeholders at large.

There is a growing body of evidence that adoption of modern contraception is enhanced by improved quality of family planning services [9]-[11]. In Tanzania, Family Planning health education (FPHE) is offered in the Reproductive and Child Health $(\mathrm{RCH})$ clinics which are 
commonly available in the first level facilities. Pregnant women and those with children below the age of five years attend these clinics regularly. During these visits, FPHE is delivered by an assigned nurse as group education. Women who show interest in any family planning method will then receive individualized education on choosing a suitable method.

Acceptance of education, perceived as translating into knowledge and use, would thus serve to decrease the unmet need for contraception in Tanzania. Clients must, therefore, have satisfactory education sessions during encounters with family planning health educators in the facilities. Generally, there are few studies on clients' satisfaction on family planning services with a particular focus on FPHE in the developing world. In Tanzania, this is important especially due to existing disparities between providers and users of health services. Therefore, we conducted this study to assess clients' satisfaction with FPHE provided at $\mathrm{RCH}$ clinics among women of reproductive age in Dar-es-Salaam region, Tanzania.

\section{Methodology}

This was a health facility-based cross-sectional descriptive study among $\mathrm{RCH}$ clinic attendees during the period of November to December 2014. The study was in Dar es Salaam, the commercial capital of Tanzania with a population estimated at 5 million people and a population density of 33,133 people per square kilometer. All facilities offering family planning services were listed: stratified by ownership as public or private. One-third of facilities from each stratum (31) was deemed representative and was picked using simple random numbers. From each facility, 8 clients were deemed enough to be able to detect a satisfaction rate of $70 \%$ at $\alpha$ error of 0.05 and $\beta$ error of 0.2 .

We approached the first eight clients who attended only for $\mathrm{RCH}$ education services. A written informed consent was then obtained to participate in the study. We used a pretested questionnaire designed to measure satisfaction with FP health education in an exit interview. Participant's demography, global rating of satisfaction, time spent at facility, ownership of the facility, and mode of payment for services were collected. Patients were dichotomized as all or none regarding satisfaction parameters.

Data was analyzed using SPSS version 24 where categorical variables were summarized as proportion, and comparisons made by chi-square tests where the significance level was set at 0.05 . Ethical approval to conduct this study was received from MUHAS IRB and permission from regional and district health authorities. $\mathrm{RCH}$ clinic providers were not informed until after the study to avoid biasing the health education on research days.

\section{RESULTS}

\section{A. Participants' Demography}

A total of 499 family planning clients were approached and all accepted to participate in the exit interviews. Most of the participants 306(61.3\%) were between 25-35 years of age. Majority of the participants were married 331(66.3\%), petty traders $(48.7 \%)$, multiparous and had primary level of education 325(65.1\%) (Table I).

TABLE I: SOCIODEMOGRAPHIC DISTRIBUTION OF CLIENTS ATTENDING

\begin{tabular}{|c|c|}
\hline Variable & Frequency $(\%)$ \\
\hline \multicolumn{2}{|l|}{ Clients' age(years) } \\
\hline$<25$ & $107(21.4)$ \\
\hline $25-35$ & $306(61.3)$ \\
\hline$>35$ & $86(17.3)$ \\
\hline \multicolumn{2}{|l|}{ Marital status } \\
\hline Single & $27(5.4)$ \\
\hline Married & $331(66.4)$ \\
\hline Separated/widow & $18(3.6)$ \\
\hline Cohabiting & $123(24.6)$ \\
\hline \multicolumn{2}{|l|}{ Education level } \\
\hline Primary and below & $325(65.1)$ \\
\hline Secondary and above & $174(34.9)$ \\
\hline \multicolumn{2}{|l|}{ Occupation } \\
\hline Housewife & $214(42.9)$ \\
\hline Petty trade & $243(48.7)$ \\
\hline Employed in formal sectors & $42(8.4)$ \\
\hline \multicolumn{2}{|l|}{ Parity } \\
\hline Null para & $11(2.2)$ \\
\hline Para 1 & $180(36.1)$ \\
\hline Para 2-4 & $276(55.3)$ \\
\hline$>$ Para 4 & $32(6.4)$ \\
\hline
\end{tabular}

\section{B. Health facilities' Characteristics}

Kinondoni district had the largest proportion of participants $49.9 \%$ reflecting on the number of health facilities in each district. Most of the health facilities were privately owned by $64.3 \%$. Nurses were the leading family planning education providers with enrolled nurse being the most by $61.9 \%$ followed by RCH Aides. Time spent at the facility was more than 30 minutes for the most, $73.1 \%$. Among all respondents, the user fee was a dominant payment modality reported by $86.2 \%$ of the participants (Table II).

TABLE II: SELECTED HEALTH FACILITIES' LOCATION, OWNERSHIP, PROVIDERS CATEGORY, TIME SPENT AND PAYMENT MODALITY IN DAR ES

\begin{tabular}{|c|c|}
\hline Variable & Frequency (n) \\
\hline \multicolumn{2}{|l|}{ District } \\
\hline Kinondoni & 249 (49.9) \\
\hline Ilala & $56(11.2)$ \\
\hline Temeke & $194(38.9)$ \\
\hline \multicolumn{2}{|l|}{ Facility Ownership } \\
\hline Private & $321(64.3)$ \\
\hline Public & $178(35.7)$ \\
\hline \multicolumn{2}{|l|}{ Provider's cadre** } \\
\hline Certificate Nurse & 309 (61.9) \\
\hline RCH Aides & $83(16.6)$ \\
\hline Diploma Nurse & $21(4.2)$ \\
\hline Nurse Officer & $22(4.4)$ \\
\hline Clinicians & $64(12.8)$ \\
\hline \multicolumn{2}{|l|}{ Time spent in a facility } \\
\hline$<30$ minutes & $134(26.9)$ \\
\hline$>30$ minutes & $365(73.1)$ \\
\hline \multicolumn{2}{|l|}{ Payment mode } \\
\hline Cash & $430(86.2)$ \\
\hline Exemption/Insurance & $69(13.8)$ \\
\hline
\end{tabular}

*Nurses fall in three categories of Certificate holders with two years training, diploma nurses with three years training and bachelor holders as nurse officers.

\section{Clients'Satisfaction}

Satisfaction was assessed in three parameters as shown in Fig. 1 below. Just an expression of overall satisfaction, 
willing to come back to same facility for similar services and ability to recommend the services to close others. The overall satisfaction with FPHE was $84 \%$ but only $78 \%$ of respondents were willing to come back to the same health facility for health education while those who were likely to recommend the health facility to relatives, friends, and family members were $82.8 \%$.

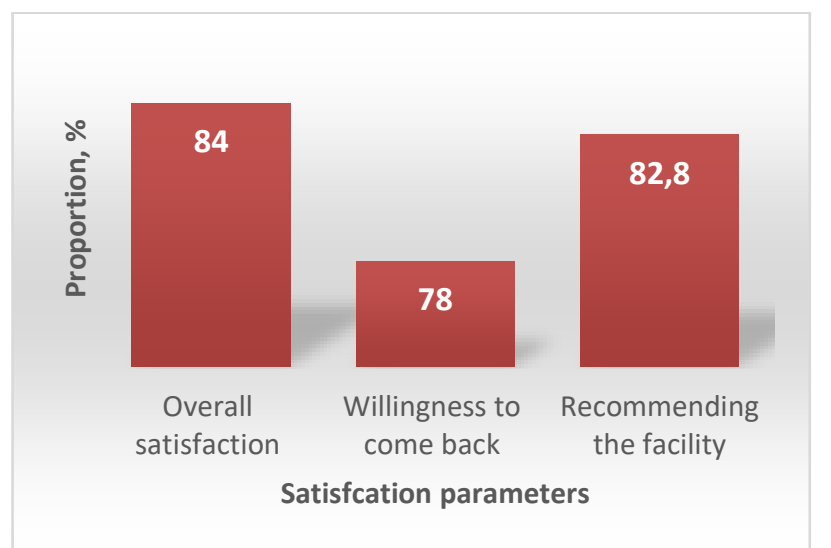

Fig. 1. Columns showing three parameters of satisfaction with family planning health education among Dar es Salaam women of reproductive age in 2014.

\section{Association between Variables and Client's Satisfaction}

As seen in Table III, only occupation and parity had a significant influence on FPHE offered: women with more than four children were $13 \%$ to $19 \%$ less likely to be satisfied with the offered education than were those with less parity and this was very significant $(\mathbf{p = 0 . 0 0 0 9})$. Similarly, the employed women were $6 \%$ more satisfied than the other occupation categories which had the greatest number of clinic attendees, a very significant occurrence ( $\mathbf{p = 0 . 0 0 0 0 1 )}$. Married couples were more satisfied than other marital categories, but this failed to reach significant levels, likewise, those over 35 years of age were more satisfied but not significantly.

TABLE III: SOCIODEMOGRAPHIC DISTRIBUTION OF CLIENTS ATTENDING

\begin{tabular}{|c|c|c|c|}
\hline Variable & $\begin{array}{c}\text { Satisfied } \\
(\%)\end{array}$ & $\begin{array}{c}\text { Not satisfied } \\
(\%)\end{array}$ & $\mathrm{P}$-value \\
\hline \multicolumn{4}{|l|}{ Age group } \\
\hline$<25$ & $84(78.5)$ & $23(21.5)$ & \multirow{3}{*}{0.3} \\
\hline $25-35$ & $259(84.6)$ & $47(15.4)$ & \\
\hline$>35$ & $76(88.4)$ & $10(11.6)$ & \\
\hline \multicolumn{4}{|l|}{ Marital status } \\
\hline Married & $283(85.5)$ & $48(14.5)$ & \multirow{3}{*}{0.5} \\
\hline Cohabiting & $101(82.1)$ & $22(17.9)$ & \\
\hline Single & $21(77.8)$ & $6(22.2)$ & \\
\hline $\begin{array}{l}\text { Separated/widow } \\
\text { Education level }\end{array}$ & $14(77.8)$ & $4(22.2)$ & \multirow{3}{*}{0.6} \\
\hline Primary and below & $275(84.6)$ & $50(15.4)$ & \\
\hline $\begin{array}{l}\text { Secondary and above } \\
\text { Occupation }\end{array}$ & $144(82.8)$ & $30(17.2)$ & \\
\hline Employed & $38(90.5)$ & $4(9.5)$ & \multirow{3}{*}{0.00001} \\
\hline Housewife & $180(84.1)$ & $34(15.9)$ & \\
\hline Petty trade & $201(82.7)$ & $42(17.3)$ & \\
\hline \multicolumn{4}{|l|}{ Parity } \\
\hline$\leq 1$ & $155(81.2)$ & $36(18.8)$ & \multirow{3}{*}{0.009} \\
\hline $2-4$ & $242(87.7)$ & $34(12.3)$ & \\
\hline$>4$ & $22(68.8)$ & $10(31.2)$ & \\
\hline
\end{tabular}

From Table IV, clients receiving service form Temeke municipality were less satisfied compared to other municipalities by between $10 \%$ to $13.7 \% \quad(\mathbf{p}=\mathbf{0 . 0 0 5})$.
Similarly, clients attended by clinicians were more satisfied than those attended by other health cadres, $\mathbf{p}=\mathbf{0 . 0 0 0 6}$. Private facilities, time spent below 30 minutes, and non-cash payment higher satisfaction was associated with but did not reach significant levels.

\section{DISCUSSION}

This is probably the first study in the literature that we know of that has attempted to understand satisfaction, specifically with FPHE, in RCH clinics in a low-middle income country (LMIC) setting. To measure satisfaction with health education offered, the study employed three parameters namely: general satisfaction, willingness to go back for the same services and readiness to recommend the facility to others. The results from this study will be crucial in addressing gaps in client's satisfaction with increasing modern contraceptive uptake.

TABLE IV: HEALTH FACILITIES' LOCATION, OWNERSHIP, PROVIDER'S CATEGORy, Time SPENT AND PAyMENT MODALiTy AS THEy INFLUENCE

\begin{tabular}{|c|c|c|c|}
\hline Variable & Satisfied (\%) & $\begin{array}{c}\text { Not satisfied } \\
(\%)\end{array}$ & P-values \\
\hline \multicolumn{4}{|l|}{ District } \\
\hline Ilala & $51(91)$ & $5(9)$ & \multirow{3}{*}{0.005} \\
\hline Kinondoni & $215(86.3)$ & 34 (13.7) & \\
\hline Temeke & $148(76.3)$ & $46(23.7)$ & \\
\hline \multicolumn{4}{|l|}{ Facility Ownership } \\
\hline Private & $275(85.7)$ & $46(14.3)$ & \multirow{2}{*}{0.16} \\
\hline Public & $144(80.9)$ & $34(19.1)$ & \\
\hline \multicolumn{4}{|l|}{ Provider's cadre } \\
\hline Clinicians & $56(87.5)$ & $8(12.5)$ & \multirow{5}{*}{0.0006} \\
\hline Nurse Officer & $12(54.5)$ & $10(45.5)$ & \\
\hline Registered Nurse & $16(76.2)$ & $5(23.8)$ & \\
\hline Enrolled Nurse & $267(86.4)$ & $42(13.6)$ & \\
\hline Clinic Aide & $63(75.9)$ & $20(24.1)$ & \\
\hline \multicolumn{4}{|c|}{ Time spent in a facility } \\
\hline$<30$ minutes & $116(86.6)$ & $18(13.4)$ & \multirow{2}{*}{0.3} \\
\hline$>30$ minutes & $303(83.0)$ & $62(17)$ & \\
\hline \multicolumn{4}{|l|}{ Payment mode } \\
\hline Non-cash & $61(88.4)$ & $8(11.6)$ & 0.3 \\
\hline Cash & $358(83.3)$ & $72(16.7)$ & \\
\hline
\end{tabular}

Overall satisfaction was higher, with 4 of 5 interviewed clients reporting being satisfied with FPHE services offered on that day of the visit. Likewise, a similar proportion was willing to go back to the same facilities for similar services in the future. However, only 3 of 4 of the clients were willing to recommend the facility to friends or relatives. With family planning faced with a lot of myths in our society, a good education strategy that satisfies clients would increase the acceptance of modern family planning services in Tanzania. Satisfaction can lead to increased and sustained utilization of any service [12] including family planning services. This high satisfaction is expected to translate into a reduction of unmet need for contraceptives which currently is at $25 \%$ of all women of reproductive age group [13.14]. Further studies to evaluate how this higher satisfaction transforms into the utilization of modern contraception methods are needed.

Higher parity was associated with less satisfaction with FPHE offered unlike what is expected [15]. This study considered higher parity to be above four children as this is the number allowed by policy. Women with more than four 
children are not willing to yield to the concept of reduced or limited family size through modern contraception. Higher satisfaction was also seen among employed women. This has never been reported before but might be due to work pressures and the current difficulties in raising families as it competes with work. Increasing women's employment in society has the potential of increasing modern contraceptive use following health education sessions.

Clients who received FPHE from clinicians were more satisfied unlike findings by others who reported higher satisfaction with nurses [16]-[18]. In reproductive health services, the nurse is the focus of patient experience hence their role becomes the key to satisfied clients. This was also demonstrated in this study whereby nurses attended fourfifth of the client load. Tanzania has three cadres of nurses with nurse officers being a degree holder hence are few in the workforce but yet were the most satisfying to the clients. Differences in the cadre and the outcome observed merits for further studies on FPHE competencies among the health cadres. A study by Bindusara et al [19] in Tanzania health facilities had revealed a serious lack of trained staff and practice guidance and this might explain the discrepancies between cadres.

Private facilities had higher satisfaction compared to public facilities, contrary to findings by other researchers [20], [21]. It is anticipated that private facilities would be more attractive than the public, but this is not the case when it comes to $\mathrm{RCH}$ clinics offering family planning services [22]. Private facilities are more likely to comply with quality and safety standards, key to satisfying services [23]. This is a promising finding as majority of women of reproductive age utilize public services.

Age of the clients, education level, and time spent at the facility did not show a significant association with the overall satisfaction. This is contrary to other findings from similar regions [24], [25], [15]. This might be due to unequal distribution in terms of socioeconomic standards among the participants. The effect of unequal distribution was also seen for payment modality whereby out-of-pocket payers were less satisfied compared to the insured and the exempted group.

Women of child bearing age are diverse, with one group wanting to stop child bearing, the other want to delay or space, and the last one want to respect nature. The diversity can seriously affect satisfaction and hence usage [26]. This calls for individualized efforts targeting those deemed to be in great need given the potential limitation in the workforce to offer individualized education sessions.

\section{CONCLUSIONS}

This study has revealed higher satisfaction rates with FPHE offered in the health facilities of the Dar es Salaam region. A higher parity, being employment status, and receiving the education from a medical doctor were found to positively influence the satisfaction. Quantifying this expressed high satisfaction into knowledge on modern family planning services is urgently needed. Strategies to increase utilization of modern family planning methods in Tanzania is needed by understanding the full determinants of modern contraceptive use by exploring health education offered to women of reproductive age.

\section{ACKNOWLEDGMENT}

We acknowledge health care providers of all the dispensaries that were involved in this study in Temeke, Kinondoni, and Ilala municipalities along with district and regional health managers for allowing us to collect data. Lastly to all women who took their busy schedule to be part of this study.

\section{FUNDING SOURCE}

This work was done of part of Master's thesis in public health hence did not receive any funding.

\section{REFERENCES}

[1] Casterline JB, Sinding SW. Unmet need for family planning in developing countries and implications for population policy. Popul Dev Rev. 2004; 26:691-723.https://doi.org/10.1111/j.17284457.2000.00691.x.

[2] Alkema L, Kantorova V, Menozzi C, Biddlecom A. National, regional, and global rates and trends in contraceptive prevalence and unmet need for family planning between 1990 and 2015: a systematic and comprehensive analysis. Lancet Lond Engl. 2013; 381:1642-52. https://doi: 10.1016/S0140-6736(12)62204-1.

[3] WHO. Unmet need for family planning. http://www.who.int/reproductivehealth/topics/family_planning/unmet need_fp/en/. Accessed 20 Apr 2018.

[4] Singh S, Darroch JE, Adding It Up: Costs and Benefits of Contraceptive Services-Estimates for 2012, New York: Guttmacher Institute and United Nations Population Fund (UNFPA), 2012. http://www.guttmacher.org/pubs/AIU-2012-estimates.pdf.

[5] Ahman E, Shah IH. New estimates and trends regarding unsafe abortion mortality. Int J Gynaecol Obstet. 2011 Nov;115(2):121-6. https://doi: 10.1016/j.ijgo.2011.05.027.

[6] Darroch JE, Singh S. Trends in contraceptive need and use in developing countries in 2003, 2008, and 2012: an analysis of national surveys. Lancet Lond Engl. 2013;381:1756-62. Lancet. 2013 May 18;381(9879):1756-62. https://doi:10.1016/S0140-6736(13)60597-8.

[7] Ahmed S, Li Q, Liu L, Tsui AO. Maternal deaths averted by contraceptive use: an analysis of 172 countries. Lancet, 2012;380(9837):111-25. https://doi: 10.1016/S0140-6736(12)60478-4

[8] World Health Organization. Working Together for Health. Geneva: World Health Organization report. https://www.who.int > whr.

[9] Hong R., Montana L, Mishra V. Family planning services quality as a determinant of use of IUD in Egypt. BMC Health Serv Res 6, 79 (2006). https://doi.org/10.1186/1472-6963-6-79.

[10] Steele F, Curtis S, Choe M. The impact of family planning service provision on contraceptive-use dynamics in Morocco. Stud Fam Plann,1999;30(1):28-42. $\quad$ https://doi: $\quad 10.1111 /$ j.17284465.1999.00028.x.

[11] RamaRao S, Lacuesta M, Costello M, Pangolibay B, Jones H. The link between quality of care and contraceptive use. Int Fam Plan Perspect,2003;29(2):76-83. htpps://doi:10.1363/ifpp.29.076.03.

[12] Larsen DL, Attkisson CC, Hargreaves WA, et al, 1979. Assessment of client/ patient satisfaction: Development of a general scale. Evaluation and Program Planning,1979;2(3);197-207. https://doi.org/10.1016/0149-7189(79)90094-6.

[13] Tanzania Demographic and Health survey 2010 report. https://www.dhsprogram.com > pubs > pdf.

[14] Boller C, Wyss K, Mtasiwa D, Tanner M. Quality and comparison of antenatal care in public and private providers in the United Republic of Tanzania. Bulletin of the World Health Organization: The International Journal of Public Health 2003;81(2):116-122 https://apps.who.int/iris/handle/10665/71717.

[15] Argago T, Hajito K, Kitila, S. Clients satisfaction with family planning services and associated factors among family planning users in Hossana Town Public health facilities, South Ethiopia. IJNM,2015; 7(5): $74-83$. htpps://doi 10.5897/IJNM 2015. 
[16] Otani K, Kurz R, Harris L. Managing primary care using patient satisfaction measures. Journal of healthcare management,2005;50(5):311-24. https://doi: 10.1097/00115514$200509000-00007$.

[17] Das P, Basu M, Tikadar T, Biswas GC, Mridha P, Pal R. Client satisfaction on maternal and child health services in rural bengal. Indian J Community Med,2010 Oct;35(4):478-81. doi: 10.4103/09700218.74344.

[18] Tung Y, Chang G. Patient's satisfaction with and recommendation of a primary care provider: association of perceived quality and patient recommendation. International Journal for Quality in Health care,2009; 21(3); 206 - 213. https://intqhc.oxfordjournals.org $21>3$ > 206.full.pdf.

[19] Bintabara D, Ntwenya J, Maro JI, Kibusi S, Gunda DW, Mpondo $\mathrm{BCT}$. Client satisfaction with family planning services in the area of high unmet need: evidence from Tanzania Service Provision Assessment Survey, 2014-2015. Reproductive Health,2018; 15:127. https://www.ncbi.nlm.nih.gov>articles>PMC6048714.

[20] Hutchinson P, Do M, Agha S. Measuring client satisfaction and the quality of family planning services: A comparative analysis of public and private health facilities in Tanzania, Kenya and Ghana. BMC Health Services Research,2011; 11:203. https://doi: 10.1186/14726963-11-203.

[21] Zwi A, Brugha R, Smith E. Private health care in developing countries. BMJ,2001;323(7311):463-4.
10.1136/bmj.323.7311.463.

[22] Kakoko DC, Ketting E, Kamazima SR, Ruben R. Provision of family planning services in Tanzania: a comparative analysis of public and private facilities. Afr J Reprod Health,2012 Dec;16(4):140-8. PMID: 23444551.

[23] Lyu H, Wick EC, Housman M, Freischlag JN, Makary MA. Patient satisfaction as a possible indicator of quality surgical care. JAMA Surg, $2013 \quad$ Apr;148(4):362-7. htpps://doi: 10.1001/2013.jamasurg.270.

[24] Yan Z, Wan D, Li L. Patient satisfaction in two Chinese provinces: rural and urban differences. Int. Int $\mathrm{J}$ Qual Health Care,2011;23(4):384-9. htpps://doi: 10.1093/intqhc/mzr034.

[25] Aldana J, Piechulek H, Al-Sabir A. Client satisfaction and quality of health care in rural Bangladesh. Bulletin of the World Health Organization,2001:79(6):512-517. htpps://doi: 10.1590/S004296862001000600006.

[26] Bhattathiry MM, Ethirajan N. Unmet need for family planning among married women of reproductive age group in urban Tamil Nadu. $\mathrm{J}$ Family Community Med. 2014;21(1):53-57. J Family Community Med,2014 Jan;21(1):53-7. Htpps://doi: 10.4103/2230-8229.128786. 